\title{
A Cross-National Analysis of Forced Population Resettlement in Counterinsurgency Campaigns
}

\author{
${ }^{1}$ University of Essex, Colchester, UK, E-mail: tbohmelt@essex.ac.uk, c.dworschak@essex.ac.uk. \\ https://orcid.org/0000-0003-0196-9545. \\ ${ }^{2}$ University Innsbruck, Innsbruck, Austria
}

\begin{abstract}
:
This article studies the forcible relocation of large segments of the society in times of war. Theoretically, our work is based on the hearts-and-minds approach for explaining counterinsurgents' strategies. We link this general framework to two more specific factors: insurgents' external support and the incumbent's status as a foreign occupier. The main contribution of our research is given by the cross-country empirical analysis, where we combine data on population displacement and counterinsurgency campaigns after World War II. We show that insurgents' external support and incumbents' status as a foreign occupier are among the main factors raising the risk of forced population resettlement. This article is a systematic, quantitative study of forced displacement across a large set of conflicts, and we demonstrate that the mechanisms behind forcible relocation as an indiscriminate strategy follow major trends across insurgencies.
\end{abstract}

Keywords: counterinsurgency, forced population resettlement, quantitative analysis

DOI: 10.1515/peps-2019-0022

\section{Introduction}

How do incumbents win counterinsurgency campaigns? Seemingly, a consensus has emerged among academics and practitioners alike that emphasizes the importance of "winning the hearts and minds" of the population (Berman \& Matanock, 2015; Dixon, 2009; Galula, 2006; Lyall, 2009; Nagl, Amos, Sewall, \& Petraeus, 2008). With this approach, the counterinsurgent seeks to gain the support of the local population via selective rewards and punishments. This, ultimately, strengthens the incumbent and, simultaneously, erodes the support base of the insurgents (see also Berman \& Matanock, 2015; Zhukov 2015; 2017). In addition, as Zhukov (2017, p. 56) points out, discriminate counterinsurgency strategies are usually less costly than indiscriminate approaches (see also Dunning \& Steele, 2011; Kalyvas, 2006; Paul, Clarke, \& Grill, 2010; Steele, 2009; Valentino, Huth, \& Balch-Lindsay, 2004; Valentino, 2014).

In light of this, however, it remains puzzling that indiscriminate violence is frequently employed in counterinsurgency campaigns. Indiscriminate targeting is a strategy that seeks to systematically eliminate an insurgency's suspected support base based on collective criteria. Generally, governments must expect increased costs from such indiscriminate strategies: first, they likely incur a loss of popular support, increasing local short-term and long-term governing costs. Second, they solve the rebels' collective action problem, as civilians suddenly fear being targeted regardless of whether they join the rebels or refrain from an active involvement in the opposition. Therefore, engaging in the conflict against the government becomes a more viable choice to many formerly non-mobilized members of society.

The following article focuses on forced population resettlement as a specific type of indiscriminate violence. Figure 1 identifies those countries whose governments have relied on this approach at least once since 1945. Several African and Asian countries, the US, the USSR/Russia, and Turkey forcibly relocated people; moreover, the UK, France, and Portugal relied on forced population resettlement in insurgency campaigns overseas. However, if forcible relocation is so costly, and arguably more so than selective counterinsurgency strategies, why do governments rely on this rather frequently as a tool to fight insurgents? 


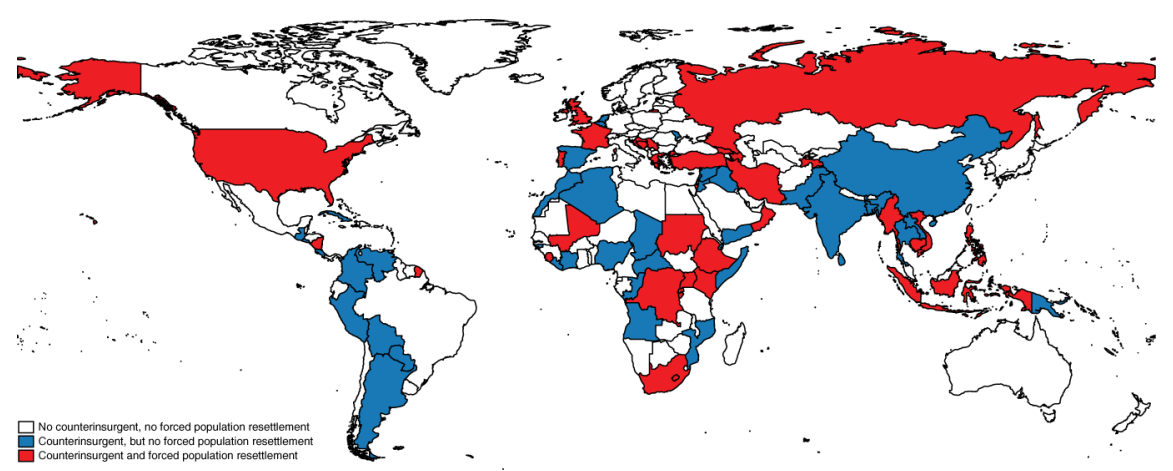

Figure 1: Counterinsurgency campaigns and forced population resettlement, 1945-2005. Graph based on data from Lyall and Wilson (2009) and Zhukov (2015), which are described in the research design.

We contribute to this debate by explaining counterinsurgents' use of forced population resettlement as an intentional strategy. Under what circumstances do governments forcibly relocate large parts of the population from one area to another (for this definition, see Petersen, 1958)? Despite the obvious importance of knowing the influences behind forced civilian resettlement, we lack knowledge on the determinants behind and consequences of this method across a larger set of cases (see also Balcells \& Steele, 2016; Dunning \& Steele, 2011; Lichtenheld, 2017; Steele 2007; 2009; Zhukov, 2015). ${ }^{1}$ A near consensus has emerged in the literature nonetheless in that the key to successfully implementing selective, discriminate strategies is information: intelligence on insurgents' whereabouts or knowledge on which segments of the population (potentially) support the opposition movement are necessary for the government to be able to apply rewards and punishments selectively (Kalyvas, 2006; Zhukov, 2015). Therefore, we argue that a lack of such information prompts the counterinsurgent to shift strategies toward more indiscriminate approaches. These include using force to relocate parts of the population to areas where they can be more easily controlled and monitored. Compared to other forms of violence, which may also result in the displacement of large parts of the population, forced displacement is intentional, with its main goal being to remove civilians from contested areas. In line with this, Kramer (2005, p. 260), for example, studies the Russian-Chechen conflict in 1999-2004 and concludes that Russia's forced population resettlement facilitated obtaining control over large territories.

We systematically examine the determinants behind forcible relocation. Our research shows that there are specific factors that determine whether the likelihood of forcible relocation being employed by the incumbent increases or not. Theoretically, our work is based on the Hearts-and-Minds approach (Dixon, 2009) and its underlying assumption that overcoming information asymmetry is key (Berman \& Matanock, 2015; Dixon, 2009; Lyall, 2009; Nagl et al., 2008). We link this general framework to two more specific factors: insurgents' external support and the incumbent's status as a foreign occupier. Furthering our knowledge about the drivers behind forced relocations addresses a critical gap in the literature. While previous research has theoretically dealt with the determinants of brute-force resettlement, the empirical evidence is largely based on single cases. For instance, Hack $(2009,2015)$ examines the British counterinsurgency strategy in Malaya and the special role of resettlement, while Lichtenheld (2017) presents qualitative evidence from Uganda and Syria. Despite important insights, the generalizability of these findings is limited and we argue accordingly for a systematic, quantitative study of the drivers behind civilian resettlement. The main contribution of this research is thus of empirical nature: we combine data on the forcible relocation of people by Zhukov (2015) with data on counterinsurgency campaigns from Lyall and Wilson (2009) since 1945. The final data set allows us to quantitatively analyze the determinants behind forced population relocations, beyond single cases, thereby presenting robust insights into states' rationale for their indiscriminate counterinsurgency strategies.

This research sheds new light on leaders' counterinsurgency policies from a policy perspective as well. While studying when states resort to forced population resettlement should clearly not "endorse" its use, it will help explaining why this practice persists in leaders' counterinsurgency approaches despite the huge costs that are commonly associated with it. We find evidence that particularly foreign occupiers rely on forced population resettlement and that governments are more likely to use it when insurgents receive support from an external party. As we argue below, these factors can be linked to governments being unable to overcome the information problem, and incumbents then use resettlement to at least control the population. In turn, our work may help policymakers and public institutions such as human-rights organizations to develop more effective policies in order to abolish the forcible relocation of people (see also Lyall, 2009). We first synthesize that governments are more likely to intentionally uproot civilians if they are unable to acquire the information necessary for applying rewards and punishments selectively (see, e.g. Greenhill, 2010; Kalyvas, 2006; Ucko, 2016). We then link this framework to two more specific factors: insurgents' external support and the incumbent's status as a foreign occupier. Our expectation is that these determinants raise the risk of incumbents relying on forcible relocation. 
Afterwards, we present the research design before we move to the empirical results. The article concludes with a summary of our findings and a discussion of implications for policymakers and future research.

\section{Information starvation and forcible relocation}

Population resettlement comes in different forms, ranging from the indiscriminate exclusion of people from society and their relocation into camps or protected villages to scorched-earth tactics, and has been employed in more than a third of all counterinsurgencies since 1945 (see, e.g. Zhukov, 2015). We follow Zhukov (2015, p. 1157-1158) and define such indiscriminate violence as "any population movement, in which people [...] are physically uprooted by a third party, in the absence of an original motivation to settle elsewhere." ${ }^{2}$ We use the terms government, incumbent, and counterinsurgent interchangeably. Agency in the performance of counterinsurgency tasks may differ, and the state actor may out-source the legitimate use of force to loyal armed groups (Carey, Mitchell, \& Lowe, 2013; Jentzsch, Kalyvas, \& Schubiger, 2015), although we do not expect this to yield salient implications for the mechanisms we propose.

Systematically resettling civilians is deemed to antagonize the population, going against the Hearts-andMinds approach (Dixon, 2009) - winning the support of the locals via selective rewards and punishments (Lyall, 2009; Schutte, 2017b). Specifically, to prevail in an insurgency, “[e]ach combatant seeks a monopoly on the use of force and pursues this goal by extracting the resources needed to maintain military operations and establish a viable state - taxes, intelligence, manpower - while denying these same resources to the opponent" (Zhukov, 2015, p. 1160). To do so, however, one needs the support of the local population (Schutte, 2017b). The government's use of indiscriminate violence under those circumstances would quickly impose the costs of conflict on the civilian population (Condra \& Shapiro, 2012), and Kalyvas (2006, p. 103) argues that civilians might then be more supportive of the insurgents as they can offer protection. ${ }^{3}$ Consider, for example, the relocation of Ugandan civilians into so-called "protected villages" in the Lord's Resistance Army (LRA) insurgency between 1996 and the mid-2000s: the Ugandan People's Defense Force intentionally uprooted up to two million people during that time (Kersten, 2016, p. 73) as the regime suspected them to (potentially) collaborate with the rebels (Soto, 2009, p. 102). As only a small minority of them actually had any active or direct links to the LRA, the crucial question is why the government would implement such an indiscriminate approach instead of trying to win the hearts and minds of the population and gain their support. As indicated above, the view of the Hearts-and-Minds approach (Dixon, 2009) is that selective rewards and punishment are more effective and less costly than indiscriminate violence (see also, e.g. Galula, 2006; Nagl et al., 2008; Paget, 1967; Thompson, 1966): collectively excluding segments of the society and targeting people may, in fact, be counterproductive and only fertilize the insurgents' recruitment efforts, since individuals will then turn to the opposition in their search for protection (Kalyvas, 2006; Kalyvas \& Kocher, 2007a; Lyall, 2009; Lyall \& Wilson, 2009; Pilster, Böhmelt, \& Tago, 2016; Sullivan, 2016; Zhukov, 2017).

However, even if counterinsurgents may prefer the implementation of the Hearts-and-Minds approach over indiscriminate strategies, one major challenge is the lack of information to distinguish between rebels and "regular" civilians. While indiscriminate violence does not solve the information problem as such, it might establish population control so that the insurgency will find it more difficult to sustain their fight against the government (Kalyvas, 2006; Lyall, 2009; Lyall \& Wilson, 2009; Pilster et al., 2016; Zhukov 2015; 2017). In more detail, winning the hearts and minds of the population depends on the ability to discriminate normal segments of the population from insurgents, and this requires detailed knowledge about individual alignments (Kalyvas, 2006, p. 173). But the regime might not have the means to acquire such information in the first place (Kalyvas, 2006, p. 174). This suggests that under information starvation (see Lyall \& Wilson, 2009, p. 77), selective targeting becomes increasingly difficult, and collective violence more attractive as it can at least establish control of the population (see, e.g. Mason \& Krane, 1989; Valentino et al., 2004). The Ugandan military simply did not have the information on who belonged to the insurgents and who did not, nor had it the capacity to acquire this information, and thus excluding entire communities via relocation seemed to be a more promising approach to drain the support for the insurgency movement (Finnström, 2008; Kersten, 2016, pp. 141-145). As a result, forced resettlement is commonly employed as a form of indiscriminate violence: large segments of the population are deported, without taking into account which families might be loyal to the regime and which could be rebel collaborators. Although the incumbent remains unable to selectively target insurgents and earning locals' support remains equally unlikely, the government can - even without much information - deny rebels their support base by resettling the civilian population to areas where they can be effectively monitored and controlled. This way, they are excluded from the access of and contact with the opposition. Accordingly, population resettlement is driven by the government's own inability to overcome the identification problem and to use selective approaches. The main purpose behind forcibly resettling people thus is to cut off the insurgents' 
base of support and recruitment (Kalyvas, 2006; Zhukov, 2015, p. 1157). Zhukov (2015, p. 1162) highlights here that forced resettlement offers to "physically prevent civilians from cooperating with rebels." In the following, we identify two main avenues through which information asymmetry leads to forced resettlement.

First, if insurgents can rely on external support, they have an additional capability source (Peic, 2014; Zhukov, 2017). This implies that insurgents have more power projection capabilities at their disposal, and that it will be more difficult for the counterinsurgent to decrease the asymmetry in information (Valentino et al., 2004). Similarly, Salehyan, Siroky, and Wood (2014) and Wood (2010) find that increased insurgent capabilities enable them to offer more incentives to civilians (e.g. protection), but also makes them more capable to punish civilians not supportive of their cause. Increased rebel capabilities render it more difficult for the counterinsurgent to capture or neutralize them (Kalyvas \& Kocher, 2007b), as well as inhibit the government's ability to gather intelligence, as this depends on a secure environment that "forms the foundation for building personal relationships with the population which can produce reliable intelligence" (Duyvesteyn, 2011, p. 456). These mechanisms should make it less likely that a counterinsurgent will prevail against the rebels as these "then have the advantage in selectivity" (Zhukov, 2015, p. 1163). Therefore, a government may employ forced resettlement as a response to its inferiority and inability to selectively target the rebels. The key here is that indiscriminate resettlement may actually be less costly, and potentially more effective, than discriminate approaches, the smaller the underlying civilian population potentially supporting the insurgents (Downes, 2007, p. 438). As a consequence, indiscriminately resettling regional segments of the population is rendered more useful to get hold of any domestically residing adversaries. Consider the following two examples that underline how an increase in insurgent capabilities makes it more difficult for counterinsurgents to overcome information asymmetry. On one hand, Kalyvas and Kocher (2007b) underline the difficulties the US faced during the Vietnamese civil war: according to the authors, only " 1 percent of actual Vietcong [were] captured or killed and about 86 percent of innocents victimized" (Kalyvas \& Kocher, 2007b, p. 201), showcasing their capacity to evade violence. On the other hand, Bhavnani, Miodownik, and Hyun Jin Choi (2011) examine the use of selective violence in Israel, the West Bank, and Gaza. They find that with disproportionally more resources, highly selective violence by the counterinsurgent becomes possible. However, stronger insurgents go against this ability.

Second, Lyall and Wilson (2009) report that a counterinsurgent's status as a foreign occupier has a negative effect on the likelihood of winning a campaign. This mirrors Zhukov (2017, p. 58) who shows that "when a government's support base lies outside the immediate conflict zone, history suggests that civilians in that conflict zone suffer more." While an insurgency against a foreign occupier might raise "nationalist sentiments" (Lyall \& Wilson, 2009, p. 86), it seems more important for our context that a foreign occupier will find it more challenging to have or gather information from the population. Zhukov $(2017$, p. 56f) contends here that foreign occupiers are particularly dependent on local information as there is no external substitute for this. Yet, acquiring this information in the first place is more difficult for them than "regular" incumbents, since they are less embedded in the local population. For example, outside parties may be less aware of regional cleavages, territory, and other information that may be key for winning their campaign (see also Schutte, 2017a). Information asymmetry should therefore increase with the status of a foreign occupier. Among others, Valentino (2014, p. 96) highlights the difficulties of states seeking to conquer or annex foreign territory, making them more likely to resort to indiscriminate approaches as these seem the only viable option. Forced resettlement of the population is unlikely to be an exception here. Ultimately, if the theoretical mechanisms linking forcible relocations to information asymmetry are valid, we should observe a higher risk of forced population resettlement in cases with external support for the insurgents and foreign occupiers.

\section{Research design}

\subsection{Data, dependent variable, and methodology}

For the empirical analysis, we employ the (counter-)insurgency campaign data by Lyall and Wilson (2009) as the data frame. These data originally comprise information on 286 insurgencies between 1800 and 2005, using the campaign as the unit of analysis. As discussed in Pilster and Böhmelt (2014, p. 3), "Lyall and Wilson (2009) focus exclusively on insurgencies in which rebels resorted to guerrilla warfare as defined through 'hit-and-run' tactics and the attempt to win the allegiance of the civilian population." Therefore, the Lyall and Wilson (2009) data are well suited to test our argument. We restrict the time period of our sample to the post-World War II period (1945-). On one hand, data for some of our explanatory variables (discussed below) are not available before 1945. On the other hand, by limiting our sample to the period after World War II, we significantly increase the degree of homogeneity of our cases. Our final sample comprises 135 insurgency campaigns.

Against this background, we use the information in Zhukov (2015) to code a binary item on forced resettlement, which we employ as the dependent variable in the following analysis. ${ }^{4}$ This item receives the value 
of 1 when Zhukov (2015) coded a campaign as having seen systematic population resettlement by the incumbent government (the counterinsurgent) and 0 otherwise. The coding of this variable is based on the definition outlined above, while discriminate relocations are omitted from the data. The variable further captures resettlements at any point in time during a counterinsurgency campaign. ${ }^{5}$ Examples for forced population resettlement as indiscriminate strategy in our data include, e.g. the forced relocations during the Strategic Hamlet Program of the US and South Vietnam (1965-1975). A complete list of forcible relocations is given in the Online Appendix. Eventually, 48 (35.56 percent) out of the 135 campaigns since World War II have seen at least some form of regimes intentionally uprooting the civilian population, while 87 (64.44 percent) have not. Due to the dichotomous nature of our outcome variable, we use logistic regression models and employ robust standard errors to address bias stemming from heteroscedasticity.

\subsection{Explanatory variables}

The main explanatory variables are insurgents' external support and the incumbent's status as a foreign occupier. First, following Lyall and Wilson (2009, p. 84f), we operationalize support by (a) whether insurgents received "material economic and military aid" and the rebels" "ability to use a neighboring country as a sanctuary." This also mirrors the emphasis on military power in Valentino et al. (2004, p. 386). After having combined the two types of information, the final variable Insurgents' Support receives the value of 0 if no external support (however defined) has been received, the value of 1 if any of the two types has been received, and the value of 2 if insurgents could benefit from both types of external support. In our sample, 47 (34.81 percent) out of 135 campaigns have not seen any external support for the insurgents, rebels in 39 campaigns (28.89 percent) received "some" support from a third party, and 49 insurgencies ( 36.30 percent) received material aid and had an external sanctuary. Out of these 49 fully supported insurgencies, 26 have seen forced relocations; and seven resettlement cases occurred when rebellions were partly supported. Second, we take the binary variable (External Occupier) from Lyall and Wilson (2009), which receives a value of 1 if the incumbent was a foreign occupying force ( 0 otherwise). In the post-World War II period, 33 out of 135 campaigns (24.44 percent) are coded as 1, of which 17 have seen forced resettlements, while about three quarters of our cases (102 out of 135) are coded as 0 .

We also control for additional variables, which can be seen as alternative determinants of forced population resettlement (see also Friedman, 2011). Unless specified otherwise, all controls are lagged 1 year before an insurgency broke out. First, there is trade openness, i.e. the sum of imports and exports as a share of GDP. The variable is log-transformed. Lyall and Wilson $(2009$, p. 84$)$ argue that governments more embedded in the international system are more sensitive to "international pressure arising from normative commitments." A larger degree of embeddedness is likely to be tied to more international, normative pressures and states' corresponding vulnerability to "reputational and economic costs for contravening existing norms" (Lyall \& Wilson, 2009; Zhukov, 2015, p. 84). Moreover, countries more strongly linked to the global market will find it easier to acquire resources for their counterinsurgency campaign, making it less likely that they have to rely on more extreme counterinsurgency strategies such as forcible relocations. Our variable, Trade Openness $(\ln )$ is taken from Lyall and Wilson (2009) who combined the information on trade from the International Monetary Fund with GDP data from the Banks Cross-National Time Series Dataset. These data are only available in the post-World War II era.

Second, we expect the size of the incumbent's military to be negatively associated with forced population resettlement. Infantry personnel makes it not only more likely that the government is able to obtain local information (Lyall \& Wilson, 2009), but a larger military as such also means that the incumbent has more military resources at their disposal to defeat the insurgents in combat. We capture the incumbent's capabilities with the number of military personnel (in thousands and log-transformed), which we take from the Correlates of War project (Singer, 1987). ${ }^{6}$ Related to this factor is our regime-type item, Democracy. We use the polity2 variable from the Polity IV project (Marshall \& Jaggers, 2016). Values theoretically range between -10 (full autocracy) and +10 (full democracy). We do not have clear expectations on this item as Zhukov (2015), for example, shows that both democracies and autocracies have made use of forced population resettlement.

Finally, there is Elevation (ln) and Cold War. The former is "the natural log of average of five elevation readings in conflict area (in meters)" and taken from Lyall and Wilson $(2009$, p. 85). We use this item to proxy rough and difficult terrain, which generally offers insurgents refuge from the government. The latter variable captures potentially idiosyncratic dynamics in the period from 1945 to 1989 . For example, states' willingness to fight and engage in other conflicts ("proxy wars") before 1990 significantly differed from the post-Cold War era. The same temporal trends might apply to the reliance on forced resettlement as a counterinsurgency strategy. Understandings and rules that change over time could influence governments' strategies, and forcible relocations are unlikely to be an exception here. Including the Cold War dummy controls for these and other forces surrounding temporal dynamics. ${ }^{7}$ 
Table 1 gives an overview of the descriptive statistics of our variables. Given that about 36 percent of our cases are characterized by forced population resettlement, it is unlikely that this can be considered a "rare event." At the same time, there is a sufficient amount of variation in the outcome and our sample is relatively balanced. Multicollinearity, according to the variance inflation factors (VIFs), is unlikely to be a major issue for our analysis. Below, we nevertheless show that our results do not depend on the inclusion or exclusion of the control covariates.

Table 1: Descriptive statistics.

\begin{tabular}{|c|c|c|c|c|c|c|}
\hline Variable & Mean & Std. dev. & Min. & Max. & Obs. & VIF \\
\hline Forced population resettlement & 0.356 & 0.480 & 0 & 1 & 135 & \\
\hline Insurgents' support & 1.015 & 0.846 & 0 & 2 & 135 & 1.15 \\
\hline External occupier & 0.244 & 0.431 & 0 & 1 & 135 & 1.47 \\
\hline Trade openness $(\ln )$ & -3.667 & 1.202 & -9.284 & -0.465 & 135 & 1.50 \\
\hline Military personnel (ln) & 4.460 & 2.029 & 0.000 & 9.433 & 135 & 1.98 \\
\hline Elevation $(\ln )$ & 6.001 & 1.340 & 0.000 & 8.497 & 135 & 1.01 \\
\hline Democracy & -0.326 & 7.018 & -10 & 10 & 135 & 1.24 \\
\hline Cold war & 0.230 & 0.422 & 0 & 1 & 135 & 1.06 \\
\hline
\end{tabular}

\section{Empirical analysis}

Table 2 summarizes the main empirical models. The first model focuses on our core explanatory variables only, i.e. Insurgents' Support and External Occupier. Clarke (2005, 2009), for instance, contends that controls may actually increase the bias in coefficient estimates instead of decreasing it, and demonstrating the robustness of our findings without controls seems therefore an effort worth making. Model 2 then drops the main independent variables and incorporates the control covariates only. Finally, Model 3 constitutes our core model as both the main explanatory items and the controls are jointly considered. For assessing the models' fit, we report logarithmic (pseudo) likelihoods, $\chi^{2}$ test statistics, and the area under the Receiver Operator Characteristic (ROC) curve. The latter is based on an in-sample prediction approach and theoretically varies between 0.5 (no predictive power) and 1.0 (perfect predictive power). We further assess the predictive validity of the results via the predicted proportional reduction in error (Herron, 2000). Since coefficients in logistic regression models cannot be directly interpreted in terms of their substance and effect sizes, we report first difference estimates in Table 3 and predicted probabilities of Forced Population Resettlement in Figure 2 (for the values of Insurgents' Support) and Figure 3 (for the values of External Occupier). We also examined various alternative model specifications to assess the robustness of our findings, which are summarized in the Online Appendix.

Table 2: Forced population resettlement in counterinsurgency campaigns.

\begin{tabular}{|c|c|c|c|}
\hline & Model 1 & Model 2 & Model 3 \\
\hline Insurgents' support & $\begin{array}{l}0.593^{* *} \\
(0.237)\end{array}$ & & $\begin{array}{c}0.442^{*} \\
(0.262)\end{array}$ \\
\hline External occupier & $\begin{array}{l}0.928^{* *} \\
(0.425)\end{array}$ & & $\begin{array}{r}1.700^{* * *} \\
(0.570)\end{array}$ \\
\hline Trade openness (ln) & & $\begin{array}{r}-0.455^{* *} \\
(0.185)\end{array}$ & $\begin{array}{r}-0.564^{* * *} \\
(0.214)\end{array}$ \\
\hline Military personnel (ln) & & $\begin{array}{r}-0.089 \\
(0.114)\end{array}$ & $\begin{array}{r}-0.243^{*} \\
(0.142)\end{array}$ \\
\hline Elevation $(\ln )$ & & $\begin{array}{r}0.099 \\
(0.127)\end{array}$ & $\begin{array}{r}0.141 \\
(0.133)\end{array}$ \\
\hline Democracy & & $\begin{array}{l}-0.026 \\
(0.028)\end{array}$ & $\begin{array}{l}-0.047 \\
(0.033)\end{array}$ \\
\hline Cold war & & $\begin{array}{r}0.437 \\
(0.426)\end{array}$ & $\begin{array}{r}0.349 \\
(0.420)\end{array}$ \\
\hline Constant & $\begin{array}{r}-1.475^{* * *} \\
(0.360)\end{array}$ & $\begin{array}{r}-2.593^{* *} \\
(1.024)\end{array}$ & $\begin{array}{r}-3.483^{* * *} \\
(1.107)\end{array}$ \\
\hline Observations & 135 & 135 & 135 \\
\hline Log pseudolikelihood & -81.953 & -82.778 & -75.295 \\
\hline Prob $>\chi^{2}$ & 0.006 & 0.100 & 0.006 \\
\hline
\end{tabular}


Area under ROC curve

${ }^{*} p<0.10,{ }^{* *} p<0.05,{ }^{* * *} p<0.01$.

Robust standard errors in parentheses.

Table 3: Substantive quantities of interest.

\begin{tabular}{lrr}
\hline & First difference & Confidence interval \\
\hline Insurgents' support & 0.149 & {$[-0.009 ; 0.296]$} \\
External occupier & 0.389 & {$[0.178 ; 0.572]$} \\
Trade openness (ln) & -0.762 & {$[-0.965 ;-0.332]$} \\
Military personnel (ln) & -0.363 & {$[-0.664 ; 0.003]$} \\
Elevation (ln) & 0.154 & {$[-0.151 ; 0.393]$} \\
Democracy & -0.158 & {$[-0.327 ; 0.014]$} \\
Cold war & 0.067 & {$[-0.058 ; 0.207]$} \\
\hline
\end{tabular}

Calculations are based on Model 3.

Table entries are first difference estimates and 90 percent confidence intervals.

Calculations done while holding all other variables constant at their median values.

First, Table 2 provides strong support for the impact of Insurgents' Support and External Occupier. Regardless of the model specification, Insurgents' Support and External Occupier exert a positive and statistically significant impact on the likelihood of forced population resettlement. The statistical significance of Insurgents' Support slightly decreases in Model 3, but remains significant at the 10\% level. Our main explanatory variables are also those that most strongly contribute to the model fit: according to the ROC statistics, we obtain a value of 0.669 in Model 1, which decreases to 0.640 in Model 2 that excludes our core explanatory items. This decrease of 0.29 points underlines that Insurgents' Support and External Occupier alone are able to predict our outcome more accurately than all controls jointly. Not surprisingly, the predictive power of the full model is the largest in Table 2 with an area-under-curve value of 0.737 . These figures are further supported by the predicted proportional reduction in error.

In more substantive terms, focusing on Insurgents' Support, Table 3 shows that the predicted probability for Forced Population Resettlement $=1$ increases by about 15 percentage points when raising Insurgents' Support from its minimum (0) to its maximum (2). ${ }^{8}$ Similarly, Figure 2 depicts the predicted probability for the outcome being 1 under two different scenarios: first, when Insurgents' Support receives the value of 0, i.e. no third-party support for the insurgents; and, secondly, when Insurgents' Support =2, i.e. when rebels have received material support from abroad and could use a neighboring state as a sanctuary. We calculated these substantive quantities of interest while holding all other variables constant at their median values along the lines of King, Tomz, and Wittenberg (2000). As the probabilities are therefore simulated parameters, we present density plots that capture their distribution, and the horizontal bars at the bottom of Figure 2 signify the point estimates of the two scenarios' probabilities and their 90 percent confidence intervals. When insurgents do not receive any external support during a campaign, the predicted probability for forced population resettlement is around 17 percent. Conversely, this probability increases by about 15 percentage points to 32 percent when there were both types of external support available for the rebels, i.e. when changing Insurgents' Support to 2. Note that the confidence intervals of the probabilities' point estimates (horizontal bars) slightly overlap, which means that the difference between the two scenarios' predicted probabilities is only barely statistically significant; this mirrors the significance level of 10 percent in Model 3. 


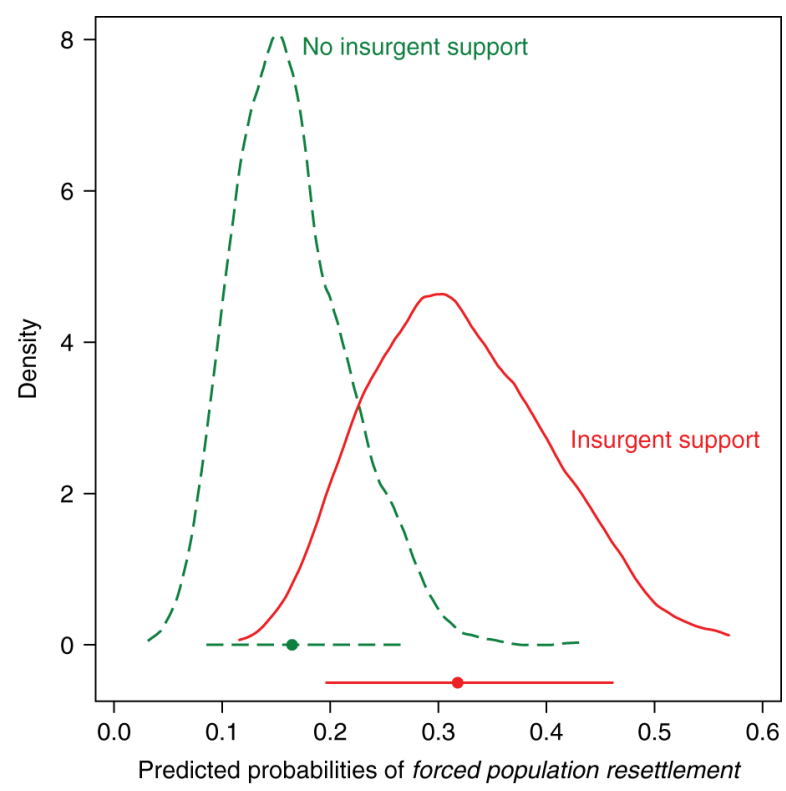

Figure 2: Predicted probabilities of forced population resettlement for minimum and maximum values of Insurgents' Support.

Note: First difference estimate, i.e. the change in the predicted probability of Forced Population Resettlement when moving Insurgents' Support from its minimum to its maximum while holding all other variables at their median values, is at around 0.149-0.153. Mean point estimate for Insurgents' Support $=0$ is at 0.165 (90 percent confidence interval: [0.085; 0.265]). Mean point estimate for Insurgents' Support $=2$ is at 0.318 (90 percent confidence interval: [0.197; 0.461]). Estimates are based on simulations ( $\mathrm{N}=1,000$ of simulated parameters), while holding all other variables at their median values. Horizontal bars in the figure pertain to 90 percent confidence intervals of probabilities' point estimates.

Second, Table 3 and Figure 3 provide strong support for our expectations regarding the effect of External Occupier. The variable's first-difference estimate is 0.389 , which highlights that foreign occupiers are substantially more likely to intentionally uproot the civilian population than purely "domestic" incumbents: the difference between the two is almost 40 percentage points, holding all else constant at the median. Moreover, Figure 3 displays the predicted probabilities associated with Forced Population Resettlement $=1$ for the "external-occupier" and the "no external occupier" scenarios. While the probability-point estimate for the latter is 23 percent, it increases to about 61 percent when focusing on the former. The confidence intervals of the two scenarios' point estimates do not overlap, which underlines that the "external-occupier" and the "no external occupier" scenaros are statistically significantly different from each other.

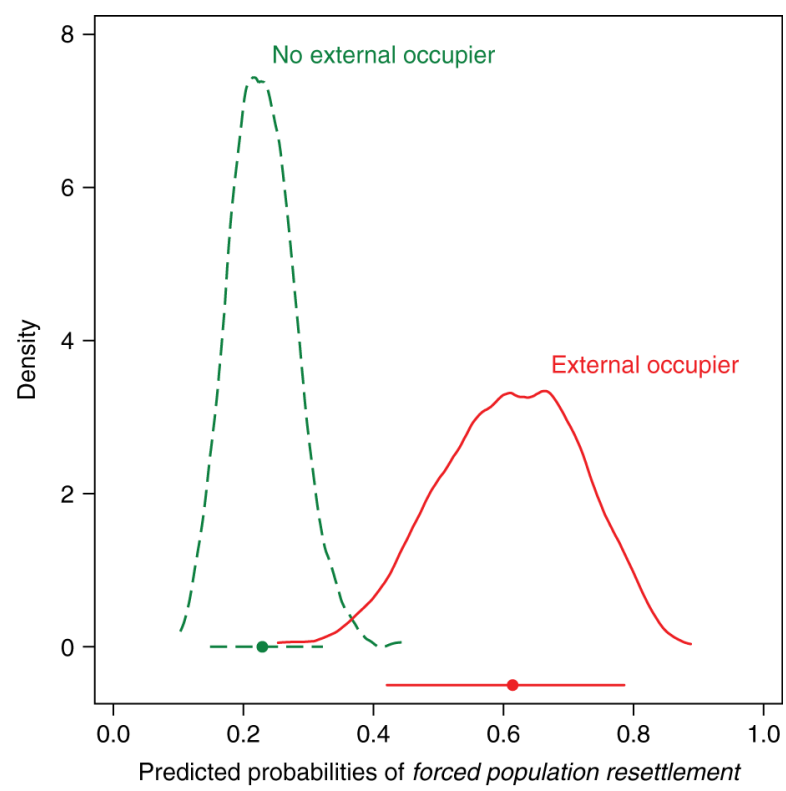


Figure 3: Predicted probabilities of forced population resettlement for minimum and maximum values of External Occupier.

Note: First difference estimate, i.e. the change in the predicted probability of Forced Population Resettlement when moving External Occupier from its minimum to its maximum while holding all other variables at their median values, is at around 0.385-0.389. Mean point estimate for External Occupier $=0$ is at 0.229 (90 percent confidence interval: [0.149; 0.322]). Mean point estimate for External Occupier $=1$ is at 0.614 (90 percent confidence interval: $[0.421 ; 0.785]$ ). Estimates are based on simulations ( $\mathrm{N}=1,000$ of simulated parameters), while holding all other variables at their median values. Horizontal bars in the figure pertain to 90 percent confidence intervals of probabilities' point estimates.

Hypothesis testing must also consider out-of-sample heuristics (see Beck, King, \& Zeng, 2000; Ward, Greenhill, \& Bakke, 2010). In order to address this, we first created separation plots for Models 1-3. Separation plots "evaluate model fit based upon the models' ability to consistently match high-probability predictions to actual occurrences of the event of interest, and low-probability predictions to nonoccurrences of the event of interest" (Greenhill, Ward, \& Sacks, 2011, p. 990). The data underlying such plots is rearranged and predicted values eventually are sorted so that actual instances of the dependent variable's events (in our case, forced relocations) are compared with these predicted values. ${ }^{9}$ For a model with reasonable predictive power, we would observe a "clustering" of most events (darker areas or bars) on the right-hand side of the plot. Figure 4 demonstrates that the models fit the data reasonably well: most "events" are clustered on the right-hand side of the figure.

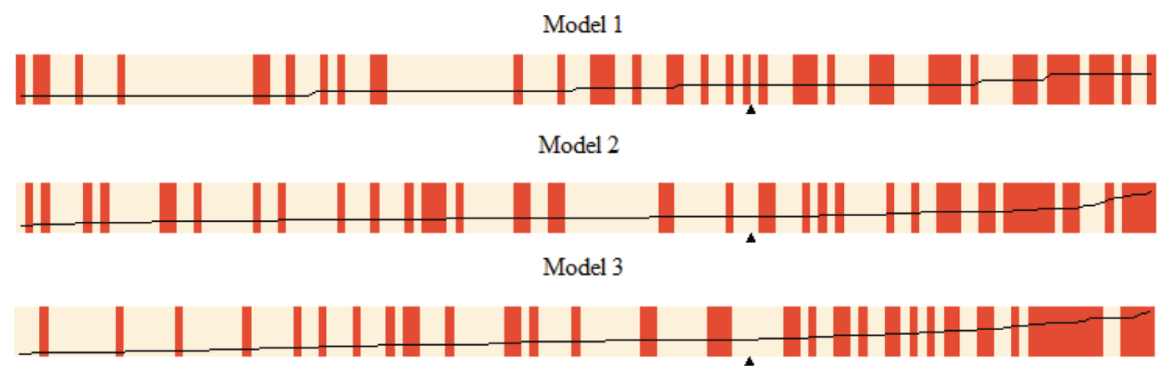

Figure 4: Separation plots: models 1-3.

Note: Solid line pertains to predicted probabilities after reordering of observations. Triangle marks expected number of events.

Second, we assess the out-of-sample predictive power of our core variables with a 4-fold cross-validation quasi-experimental exercise. We here divided the sample underlying Model 3 into four random, equally sized segments to estimate the parameters of the models with three of them. The fourth segment is retained for assessing the predictive power of the baseline model on the pooled subsets via the area under the ROC curve. We repeat this procedure 10 times and also calculate the average values of the prediction accuracy measures. Table 4 summarizes the findings: the average AUC score for the full model is lower than in the in-sample case (0.737, see Table 2$)$. However, the value remains reasonably strong and also decreases on average when omitting either Insurgents' Support or External Occupier from the estimation. These findings suggest, therefore, that both core explanatory variables do contribute to the predictive power of the model - in-sample as well as out-ofsample.

Table 4: 4-Fold cross-validation exercise - summary.

\begin{tabular}{lrrr}
\hline Cycle run & Full model & W/out insurgents' support & W/out external occupier \\
\hline 1 & 0.6753 & 0.6612 & 0.5826 \\
2 & 0.6070 & 0.6597 & 0.5893 \\
3 & 0.6212 & 0.6528 & 0.6231 \\
4 & 0.6422 & 0.6707 & 0.6317 \\
5 & 0.6568 & 0.6193 & 0.6032 \\
6 & 0.6806 & 0.6789 & 0.6123 \\
7 & 0.6743 & 0.6767 & 0.6066 \\
8 & 0.6609 & 0.6315 & 0.5879 \\
9 & 0.6830 & 0.6494 & 0.6307 \\
10 & 0.6671 & 0.6468 & 0.6070 \\
Mean AUC & 0.657 & 0.655 & 0.607 \\
\hline
\end{tabular}

Finally, Figure 5 examines the joint impact of Insurgents' Support and External Occupier. That is, holding Insurgents' Support constant at 0,1 , or 2, we calculated the predicted probabilities of our outcome being 1 according 
to the two possible values of External Occupier. On one hand, the "separate" effects pertaining to the individual variables mirror those we discussed above: both variables are positively associated with Forced Population Resettlement $=1$, which is depicted by the higher probabilities for External Occupier = 1 (regardless of the value of Insurgents' Support) and the upward trend in probability values associated with higher values of Insurgents' Support (regardless of the values of External Occupier). Figure 5 also sheds light on the "joint" effect of both variables as the risk of population resettlement is more than 70 percent when Insurgents' Support and External Occupier are set to their maximum values. Conversely, this likelihood drops to about 20 percent when Insurgents' Support and External Occupier are held at their respective minimum values. Ultimately, we conclude that our empirics strongly and robustly emphasize that incumbents select themselves strategically into counterinsurgency approaches - forcible relocations are not an exception here. Insurgents' Support and External Occupier are statistically and substantively linked to our outcome variable.

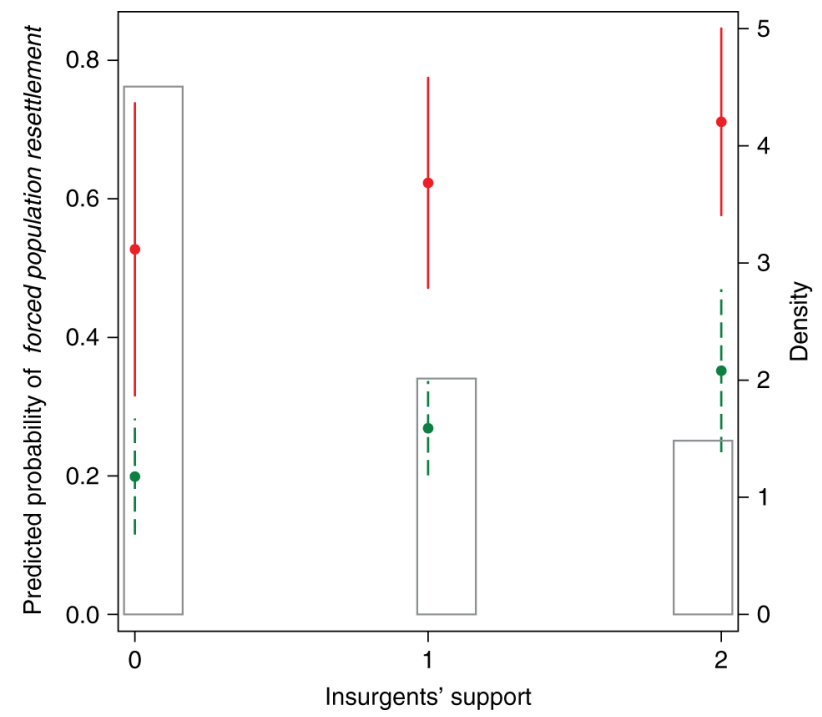

Figure 5: Predicted probabilities of forced population resettlement in different scenarios of Insurgents' Support and External Occupier.

Circles pertain to point estimates of predicted probabilities of Forced Population Resettlement. Vertical bars signify 90 percent confidence intervals.

Coming to our control items, Table 2 demonstrates that only Trade Openness (ln) achieves conventional levels of statistical significance consistently across the estimations. All else equal, countries more strongly embedded in the global trade network are less likely to employ forced population resettlement as a counterinsurgency strategy. According to Table 3, Trade Openness $(\ln )$ has a first difference estimate of -0.762 , i.e. the probability of resettlement decreases by about 76 percentage points when raising Trade Openness (ln) from its minimum to its maximum. All other variables are neither statistically nor substantively meaningful in our estimations. Adding or dropping variables and altering the operationalization of the controls does not change this conclusion, and we demonstrate this in the Online Appendix.

\section{Conclusion}

Why do governments rely on forced population resettlement as a counterinsurgency strategy - an approach that is deemed costlier than most other counterinsurgency strategies? We have taken stock of the existent literature with this article and identified that information asymmetry is one of the central problems governments face in their counterinsurgency campaigns (see, e.g. Greenhill, 2010; Kalyvas, 2006; Ucko, 2016; Zhukov, 2017; 2015). If regimes are unable to address this problem, more extreme, indiscriminate counterinsurgency strategies become increasingly more likely. This study has shown, theoretically and empirically, that forced population resettlement as an indiscriminate counterinsurgency strategy is not an exception to this and, in fact, follows the patterns of other forms of indiscriminate violence.

We linked the general implications of the Hearts-and-Minds approach, and its underlying assumption that overcoming information asymmetry is key (Berman \& Matanock, 2015; Dixon, 2009; Lyall, 2009; Nagl et al., 2008), to two more specific and directly observable factors: insurgents' external support and the status of the incumbent as a foreign occupier. With this approach, we offer the a systematic cross-country analysis of forced population resettlement, allowing us to produce generalizable findings and identify patterns that apply across 
a broad range of conflicts instead of single cases. In line with our expectations, we found that external support for rebels and the status as a foreign occupation force of the counterinsurgent significantly and substantively raise the risk of forcible relocation by the government. From a policy perspective, explaining forced population resettlement is of paramount importance both due to its frequent use and its violation of international law. Several key implications follow from our work. First and foremost, we have identified two main predictors that are associated with a higher risk of forcible relocations across insurgency campaigns. Public institutions, international organizations, and human-rights groups might use our research to develop more effective strategies, including sanctions, to effectively ban this violation of international law from regimes' counterinsurgencystrategy portfolios. In general, knowing which specific factors make it more or less likely that states rely on such indiscriminate approaches will crucially inform policy-makers' actions against rulers intentionally relocating their population. In addition, our work may also inform governments more accurately about the costs and benefits of counterinsurgency strategies, rendering forcible relocations unnecessary to begin with. For example, regimes may now seek more strongly to cut-off rebels' external support base by, e.g. controlling borders more thoroughly; this is plausibly not as costly as forced population resettlement (Zhukov, 2017, p. 59).

We believe there are also some important avenues for future research. First, further studies would greatly benefit from more disaggregated data on the scale of resettlement and its spatial resolution to identify which regions or parts of a country are more affected by and targeted for resettlement. Czaika and Kis-Katos (2009), for example, concentrate on the village level during the civil conflict in Indonesia. Investing into data collection to disaggregate the temporal dimension may also be helpful: so far, cross-conflict data do not allow to identify in which year of a counterinsurgency campaign forced relocation occurred. However, Schon (2015), for instance, illustrates the usefulness of more temporally fine-grained data with daily displacement and violence information for the case of Somalia. Similarly, determining the state's capacity at the point of relocation would be valuable in order to identify its capability of adapting alternative strategies more precisely, or to refer to other indiscriminate approaches like expulsion (see Lichtenheld, 2017).

Second, and derived from the last point, future work may also study selective deportations - a phenomenon that is related to our work, but probably requires a different theoretical rationale than what we have presented here. Given that forcible relocations could be quite costly, this strategy becomes arguably more attractive if states have the information necessary to target individuals. More generally, an examination of additional options that state leaders have at their disposal seems an effort worth making, including state-sponsored mass-killings, genocide, as well as smaller scale one-sided violence.

Third, our results provide an important first-stage basis for assessing the actual effectiveness of forced resettlement during counterinsurgency campaigns, since they enable future researchers to control for incumbents' self-selection into this strategy. Fourth, we also suggest to examine the impact of forcible relocations on postconflict stability. Is reconciliation less likely, and dispute recurrence more probable, when leaders have systematically uprooted parts of the population? Fifth, our focus in this research has been the incumbent government. Yet, insurgents frequently rely on indiscriminate violence as well. Future research may study the opposition's side and combine this with our work to develop a joint theoretical and empirical framework on the use of forced population resettlement in (counter-)insurgency campaigns.

Finally, our empirical models address associations between variables, not causation. We use a macro-level theoretical framework to explain a phenomenon that consists of a series of individual decisions. However, the hypotheses we develop and empirically examine strongly point toward the link between forced resettlement and our explanatory variables as a main explanation via the mechanisms we focus on. Having said that, we also acknowledge that our empirical findings could also be consistent with other arguments, but this requires detailed empirical analysis at the micro-level to address more thoroughly the underlying causal mechanisms driving forcible relocations.

\section{Acknowledgement}

For useful comments, we are grateful to the journal's editor, Arzu Kibris, and the anonymous reviewers. We also thank Govinda Clayton, Faten Ghosn, Kerim Can Kavakli, Cliff Morgan, Jill Schmieder Hereau, Jacqueline Hazelton, Ben Valentino, Scott Sagan, Tiffany Chu, Alexis Henshaw, Bear Braumoeller, Ayse Zarakol, Debbi Avant, Stuart Kaufman, and Cullen Hendrix for their suggestions. A version of this article has been presented at the 17. Jan Tinbergen European Peace Science Conference (Antwerp, June 26-28, 2017) and the workshop "Political, Economic, Social, and Legal Aspects of Hosting Migrants and Refugees" (Istanbul, July 4-8, 2017). 


\section{Funding}

We acknowledge funding from the Newton Fund (Funder Id: http://dx.doi.org/10.13039/100010897, grant number: RLWK6-261786650).

\section{Notes}

1 Berman and Matanock (2015, p. 456) emphasize accordingly that "counterinsurgency strategies unconstrained by rules of engagement range from forced displacement to ethnic cleansing, but we know relatively little about their use."

2 Zhukov (2015) further defines displacement by referring to instances where governments "physically remove civilians from one location and relocate them to another" and the regime "dictates the origin, destination, and timing of a population movement and imposes her choice on civilians." Finally, regimes relocate "civilians to areas where they can be more easily monitored and controlled - such as shelters, detention facilities, and camps."

3 See also Zhukov (2013), Zhukov (2015, p. 1159), Rueda (2017), or Barter (2016) for a general overview of the strategic choices civilians face in civil war.

4 The original data set is available online at: http://journals.sagepub.com/doi/suppl/10.1177/0022002713520590.

5 We return to this issue in the conclusion.

6 However, the number of troops does not provide information about the military's will or capability in terms of fighting the insurgency. Hence, in the Online Appendix, we also discuss an alternative operationalization for a country's capabilities.

7 We also examined an arguably cruder proxy for this: a dichotomous variable on whether the counterinsurgent was the UK or not. Historical accounts suggest that British counterinsurgents applied resettlements early and that they have learned to make use of them effectively. However, neither is the British dummy variable significant in our models nor are the main explanatory variables' results affected by this change in the research design.

8 We also examined the possibility of a curvilinear impact of Insurgents' Support on the dependent variable, but found little evidence for that.

9 In the words of Greenhill et al. (2011, p. 994): "[t]he key idea is that the model's fit (or predictive power) can now be evaluated by simply gauging the extent to which the actual instances of the event are concentrated at the bottom end of the table (right-hand side of the plot), and the nonevents at the top end of the table (left-hand side of the plot). A model with no predictive power - i.e. one whose outcomes can be approximated by a random coin toss - would generate an even distribution of 0 s and 1s along the column on the right-hand side."

\section{References}

Balcells, L., \& Steele, A. (2016). Warfare, political identities, and displacement in spain and colombia. Political Ceography, 51(1), 15-29.

Barter, S. (2016). Civilian strategy in Civil War: Insights from Indonesia, Thailand, and the Philippines. New York: Springer.

Beck, N., King, G., \& Zeng, L. (2000). Improving quantitative studies of international conflict: A conjecture. American Political Science Review, 94(1), 21-35.

Berman, E., \& Matanock, A. M. (2015). The empiricists' insurgency. Annual Review of Political Science, 18(1), 443-464.

Bhavnani, R., Miodownik, D., \& Hyun Jin Choi, H. J. (2011). Three two tango: Territorial control and selective violence in Israel, the West Bank, and Gaza. Journal of Conflict Resolution, 55(1), 133-158.

Carey, S. C., Mitchell, N. J., \& Lowe, W. (2013). States, the security sector, and the monopoly of violence: A new database on pro-government militias. Journal of Peace Research, 50(2), 249-258.

Clarke, K. A. (2005). The phantom menace: Omitted variable bias in econometric research. Conflict Management and Peace Science, 22(4), 341352.

Clarke, K. A. (2009). Return of the phantom menace: Omitted variable bias in political research. Conflict Management and Peace Science, 26(1), 46-66.

Condra, L. N., \& Shapiro, J. N. (2012). Who takes the blame? The strategic effects of collateral damage. American Journal of Political Science, 56(1), 167-187.

Czaika, M., \& Kis-Katos, K. (2009). Civil conflict and displacement: Village-level determinants of forced migration in aceh. Journal of Peace Research, 46(3), 399-418

Dixon, P. (2009). Hearts and minds'? british counter-insurgency from malaya to iraq. Journal of Strategic Studies, 32(3), 353-381.

Downes, A. (2007). Draining the sea by filling the graves: Investigating the effectiveness of indiscriminate violence as a counterinsurgency strategy. Civil Wars, 9(4), 420-444.

Dunning, T., \& Steele, A. (2011). ‘Electing displacement: Political cleansing in apartadó, colombia. Journal of Conflict Resolution, 55(3), 423-445

Duyvesteyn, I. (2011). Hearts and minds, cultural awareness and good intelligence: The blueprint for successful counter-insurgency? Intelligence and National Security, 26(4), 445-459.

Finnström, S. (2008). Living with bad surroundings: War, history, and everyday moments in Northern Uganda. Raleigh, NC: Duke University Press

Friedman, J. A. (2011). Manpower and counterinsurgency: Empirical foundations for theory and doctrine. Security Studies, 20(4), 556-591.

Galula, D. (2006). Counterinsurgency warfare: Theory and practice. Westport: CT: Greenwood Publishing Croup.

Greenhill, K. M. (2010). Weapons of mass migration: Forced displacement, coercion, and foreign policy. Ithaca, NY: Cornell University Press.

Greenhill, B., Ward, M. D., \& Sacks, A. (2011). The separation plot: A new visual method for evaluating the fit of binary models. American Journal of Political Science, 55(4), 991-1002.

Hack, K. (2009). The malayan emergency as counter-insurgency paradigm. Journal of Strategic Studies, 32(3), 383-414. 
Hack, K. (2015). Detention, deportation and resettlement: British counterinsurgency and malaya's rural chinese, 1948-1960. Journal of Imperial and Commonwealth History, 43(4), 611-640.

Herron, M. C. (2000). Postestimation uncertainty in limited dependent variable models. Political Analysis, 8(1), 83-98.

Jentzsch, C., Kalyvas, S. N., \& Schubiger, L. I. (2015). Militias in Civil Wars. Journal of Conflict Resolution, 59(5), 755-769.

Kalyvas, S. N. (2006). The logic of violence in Civil War. Cambridge: Cambridge University Press.

Kalyvas, S. N., \& Kocher, M. A. (2007a). How “free" is free riding in civil wars?: Violence, insurgency, and the collective action problem. World Politics, 59(2), 177-216.

Kalyvas, S. N., \& Kocher, M. A. (2007b). How "free" is free riding in Civil Wars? Violence, insurgency, and the collective action problem. World Politics, 59(2), 177-216

Kersten, M. (2016). Justice in conflict: The international criminal court's impact on conflict, peace, and justice. Oxford: Oxford University Press.

King, G., Tomz, M., \& Wittenberg, J. (2000). Making the most of statistical analyses: Improving interpretation and presentation. American Journal of Political Science, 44(2), 347-361.

Kramer, M. (2005). Guerrilla warfare, counterinsurgency, and terrorism in the north caucasus: The military dimension of the russian-chechen conflict. Europe-Asia Studies, 57(2), 209-290.

Lichtenheld, A. G. (2017). An assortative theory of civilian displacement in Civil Wars: Theory and preliminary evidence. Typescript: University of California, Berkeley, CA.

Lyall, J. (2009). Does indiscriminate violence incite insurgent attacks? Evidence from chechnya. Journal of Conflict Resolution, 53(3), 331-362.

Lyall, J., \& Wilson, I. (2009). Rage against the machines: Explaining outcomes in counterinsurgency wars. International Organization, 63(1), 67-106.

Marshall, M. J., \& Jaggers, K. (2016). Polity IV project: Political regime characteristics and transitions, 1800-2015. Users' manual. College Park, MD: University of Maryland.

Mason, T. D., \& Krane, D. A. (1989). The political economy of death squads: Toward a theory of the impact of state-sanctioned terror. International Studies Quarterly, 33(2), 175-198.

Nagl, J., Amos, J., Sewall, S., Petraeus, D. (2008). The US army/marine corps counterinsurgency field manual. Chicago, IL: University of Chicago Press.

Paget, J. (1967). Counter-insurgency operations: Techniques of guerilla warfare. New York: Walker.

Paul, C., Clarke, C. P., \& Crill, B. (2010). Victory Has a Thousand Fathers: Sources of Success in Counterinsurgency. Washington, DC: Rand Corporation.

Peic, G. (2014). Civilian defense forces, state capacity, and government victory in counterinsurgency wars. Studies in Conflict \& Terrorism, 37(2), 162-184.

Petersen, W. (1958). A general typology of migration. American Sociological Review, 23(3), 256-266.

Pilster, U., \& Böhmelt, T. (2014). Predicting the duration of the syrian insurgency. Research \& Politics, 1(2), 1-10.

Pilster, U., Böhmelt, T., \& Tago, A. (2016). The differentiation of security forces and the onset of genocidal violence. Armed Forces $\&$ Society, $42(1), 26-50$.

Rueda, M. R. (2017). Popular support, violence, and territorial control in civil war. Journal of Conflict Resolution, 61, 1626-1652.

Salehyan, I., Siroky, D., \& Wood, R. M. (2014). External rebel sponsorship and civilian abuse: A principal-agent analysis of wartime atrocities. International Organization, 68(3), 633-661.

Schon, J. (2015). Focus on the forest, not the trees: A changepoint model of forced displacement. Journal of Refugee Studies, 28(4), 437-467.

Schutte, S. (2017a). Ceographic determinants of indiscriminate violence in civil wars. Conflict Management and Peace Science, 34(4), 380-405.

Schutte, S. (2017b). Violence and civilian loyalties: Evidence from Afghanistan. Journal of Conflict Resolution, 61(8), 1595-1625.

Singer, J. D. (1987). Reconstructing the correlates of war dataset on material capabilities of states, 1816-1985. International Interactions, 43(4), $115-132$.

Soto, C. R. (2009). Tall grass: Stories of suffering and peace in Northern Uganda. Kampala: Fountain Publishers.

Steele, A. (2007). Massive civilian displacement in Civil War: assessing variation in Colombia. HiCN Working Papers 29, Households in Conflict Network. http://www.hicn.org/wordpress/wp-content/uploads/2012/06/wp29.pdf.

Steele, A. (2009). Seeking safety: Avoiding displacement and choosing destinations in civil wars. Journal of Peace Research, 46(3), 419-429.

Sullivan, C. M. (2016). Political repression and the destruction of dissident organizations. World Politics, 86(4), 645-676.

Thompson, R. (1966). Defeating communist insurgency: The lessons of Malaya and Vietnam. London: Chatto and Windus.

Ucko, D. H. (2016). The people are revolting: An anatomy of authoritarian counterinsurgency. Journal of Strategic Studies, 39(1), $29-61$.

Valentino, B. A. (2014). Why we kill: The political science of political violence against civilians. Annual Review of Political Science, 17(1), 89-103.

Valentino, B., Huth, P., \& Balch-Lindsay, D. (2004). “Draining the sea:” Mass killing and guerrilla warfare. International Organization, 58(2), 375-407.

Ward, M. D., Greenhill, B. D., \& Bakke, K. M. (2010). The perils of policy by p-value: Predicting civil conflicts. Journal of Peace Research, 47(4), 363-375.

Wood, R. M. (2010). Rebel capability and strategic violence against civilians. Journal of Peace Research, 47(5), 601-614

Zhukov, Y. M. (2013). An epidemic model of violence and public support in civil war. Conflict Management and Peace Science, 30(1), 24-52.

Zhukov, Y. M. (2015). Population resettlement in war: Theory and evidence from soviet archives. Journal of Conflict Resolution, 59(7), 1155-1185.

Zhukov, Y. M. (2017). External resources and indiscriminate violence: Evidence from german-occupied belarus. World Politics, 69(1), 54-97.

Supplementary Material: The online version of this article offers supplementary material (DOI: https://doi.org/10.1515/peps-2019-0022). 